\title{
Polar Head Modified Phospholipids by Phospholipase D-Catalyzed Transformations of Natural Phosphatidylcholine for Targeted Applications: An Overview
}

\author{
Chiara Allegretti ${ }^{1, *(D)}$, Francesca Denuccio ${ }^{2}$, Letizia Rossato ${ }^{2}$ and Paola $D^{\prime}$ Arrigo ${ }^{1,3, *(D)}$ \\ 1 Department of Chemistry, Materials and Chemical Engineering “Giulio Natta”, Politecnico di Milano, \\ via Mancinelli 7, 20131 Milano, Italy \\ 2 Department of Biotechnology and Biosciences, University of Milano-Bicocca, 20126 Milano, Italy; \\ f.denuccio@campus.unimib.it (F.D.); 1.rossato1@campus.unimib.it (L.R.) \\ 3 Consiglio Nazionale delle Ricerche (C.N.R.), Istituto di Scienze e Tecnologie Chimiche "Giulio Natta", \\ SCITEC, via Mancinelli 7, 20131 Milano, Italy \\ * Correspondence: chiara.allegretti@polimi.it (C.A.); paola.darrigo@polimi.it (P.D.)
}

Received: 28 July 2020; Accepted: 13 August 2020; Published: 1 September 2020

check for updates

\begin{abstract}
This review describes the use of phospholipase D (PLD) to perform the transphosphatidylation of the most common natural phospholipid (PL), phosphatidylcholine (PC) to obtain polar head modified phospholipids with real targeted applications. The introduction of different polar heads with distinctive physical and chemical properties such as charge, polarity and dimensions allows the obtainment of very different PLs, which can be exploited in very diverse fields of application. Moreover, the inclusions of a bioactive moiety in the PL polar head constitutes a powerful tool for the stabilization and administration of active ingredients. The use of this biocatalytic approach allows the preparation of compounds which cannot be easily obtained by classical chemical methods, by using mild and green reaction conditions. PLD is a very versatile enzyme, able to catalyze both the hydrolysis of PC to choline and phosphatidic acid (PA), and the transphosphatidylation reaction in the presence of an appropriate alcohol. The yield of production of the desired product and the ratio with the collateral PA formation is highly dependent on parameters such as the nature and concentration of the alcohol and the enzymatic source. The application of PLD catalyzed transformations for the production of a great number of PLs with important uses in medical, nutraceutical and cosmetic sectors will be discussed in this work.
\end{abstract}

Keywords: phospholipase D; phospholipids; transphosphatidylation

\section{Introduction}

Phospholipids (PLs) are amphiphilic molecules that are ubiquitous in nature and play a fundamental structural role in all biological membranes [1-3]. These molecules present a glycerol backbone which is linked to two fatty acid-derived acyl residues at the carbon positions $s n-1$, sn-2 and to a phosphodiester group bearing a polar head at the $s n-3$ position, as reported in Figure 1.

PL molecules, therefore, present a hydrophobic moiety comprising the two fatty acid chains which may be either saturated or unsaturated, the glycerol backbone of intermediate polarity and a polar hydrophilic head group. Most of the different classes of PLs are defined by the nature of the polar head, but their structural diversity can also be linked to the type of the fatty acid substituents and their regioisomerism. PLs are widely studied and investigated as they are biologically active compounds. Besides being the major component of all biological membranes, they present excellent biocompatibility and have very interesting applications by virtue of the intrinsic properties of the individual molecules 
themselves. They are a nutritious source of fatty acid, organic phosphate and choline, and they are recognized to possess beneficial effects to human health $[4,5]$. For these reasons, they are the topic of many areas of biomedical research, and they can generate model systems of biological membranes for specific studies [6]. In fact, they are implicated in many cellular functions. They are involved in processes of cellular regeneration and differentiation in neurological pathways; they are able to promote the biological activity of various membrane linked proteins and receptors; they play an important part for molecule transportation through the cell membrane; and they can be used as diagnostic markers for certain diseases and therapeutic agents [7]. Dietary PLs are essential for preventing a range of human diseases such as coronary heart disease, cancer and inflammation [8,9]. Furthermore, the amphiphilic nature of these molecules is the key factor responsible for their unique property of spontaneous aggregation in aqueous environments. They are able to self-associate spontaneously forming supramolecular structures such as bilayers, micelles and liposomes, and this characteristic is very appealing for the drug delivery, diagnostic testing and cosmetic sectors [10-14]. The PL based drug delivery system has been found to provide an effective delivery of drugs, and a great variety of PLs formulations has been used for clinical applications $[15,16]$. In particular, the gastro-resistance of liposomes is the key factor in the formulation of bioactive molecules: vitamins, antioxidants, essential oils, flavors, enzymes and fatty acids are some examples of products encapsulated therein. Additionally PLs possess considerable industrial interest as emulsifiers, food stabilizers, antioxidants, detergents and surfactants [17-19]. All these applications lead to a strong demand for PL preparation methodologies $[5,15,20,21]$.

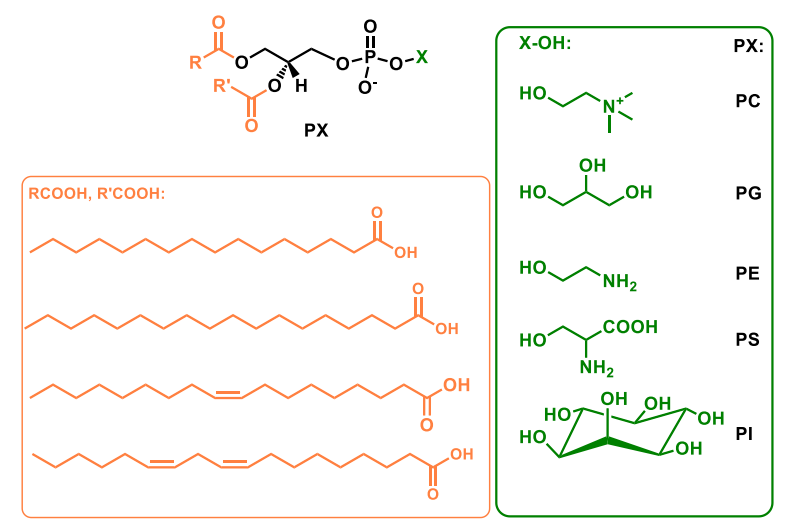

Figure 1. Structure of the main natural phospholipids (PLs) (PC: phosphatidylcholine; PG: phosphatidylglycerol; PE: phosphatidylethanolamine; PS: phosphatidylserine; PI: phosphatidylinositol).

PLs are widely distributed in nature and can be obtained from animal products such as milk, egg yolk, krill, bovine brain and from vegetable sources such as soybeans, sunflower, corn, peanut, flaxseed, rape (canola) seed and wheatgerm [22,23]. The term lecithin refers to a mixture of PLs extracted both from animal and vegetable sources which provide a different composition of PLs in terms of polar heads and acyl chains. Nowadays, lecithins are typically extracted industrially by treatment of vegetable oils, soy beans, egg yolk, milk, biomass and animal organs [22]. The principle sources in terms of quantity for commercial lecithins are egg yolk and soybeans. Lecithins are mainly composed by PLs, triglycerides, carbohydrates and minor components [24]. The most common PLs present in lecithins are phosphatidylcholine (PC), phosphatidylethanolamine (PE) and phosphatidylinositol (PI). The commercial value of PLs in the pharmaceutical, cosmetic and food industry increases with the purity of the product, which refers to the nature of polar head and lipophilic tails which are fundamental for obtaining the desired functions $[25,26]$. In fact, the chemical and physical properties of PLs depend on their molecular structure in terms of the nature of the polar head group and fatty acid composition, which is highly linked to their origin. For natural PLs, it is well known that the purer they are, the higher the price. Partial purification of PLs from lecithins is possible after many steps of 
solvent partitioning and chromatographic separations. In this way, PC, the most abundant natural PL, can be isolated and purified. However, the obtainment of other specific minor PLs that rarely exist in nature is quite difficult and suffers the high cost of chromatographic separation, which makes it inappropriate for the purification of PLs in industrial processes.

The preparation of well-defined and novel PLs is also at the base of the investigation of their potential properties. There is a great interest in producing a wide variety of innovative PLs with modulated chemical and physical properties, such as charge, size, polarity, type of polar head or side chains, for diverse uses. Some applications require, in fact, the preparation of PLs with specific polar heads and different and defined acyl chains at the $s n-1$ and $s n-2$ positions $[27,28]$. The preparation of these products is challenging and can be obtained by total synthesis from appropriate homochiral precursors (such as glycerol derivatives) by performing a multistep synthesis which generally requires the use of a complex sequence of protection and deprotection steps in order to introduce the desired functional groups [29-32]; however, this aspect is beyond the focus of this review. A biocatalytic approach aiming to synthesize the modified PLs is preferred if compared to the chemical synthesis especially if the product's destination is for the food or pharmaceutical industry because of the use of harmless, natural and much safer reagents [33-35]. The use of enzymes offers a higher selectivity; it allows the use of milder conditions by avoiding the use of strong, unsafe and often corrosive reagents; and permits the obtainment of products which cannot easily be achieved by classical chemical methods.

PLs have two carboxylic and two phosphate ester bonds: their enzyme-mediated modification includes hydrolysis, transphosphatidylation and transesterification. The enzymes involved in these transformations are called phospholipases and are selective for one of the four ester bonds present in the molecules of PLs, as described in Figure 2 for natural PC (reported as 1-palmitoyl-2-linoleyl-PC). Phospholipases $\mathrm{A}_{1}\left(\mathrm{PLA}_{1}, 3.1 .1 .32\right) / \mathrm{A}_{2}$ (PLA 2 , 3.1.1.4) remove, respectively, the fatty acids in position $s n-1$ and $s n-2$ producing 2-acyl and 1-acyl-lysophospholipids (1-lysoPL and 2-lysoPL) [29]. Phospholipase C (PLC, E.C.3.1.4.3) cleaves the phosphoric ester on the glycerol side [36] and phospholipase D (PLD, E.C.3.1.4.4) on the polar head side [37]. Phospholipases are widespread in nature playing very different physiological roles [38,39]. Enzymes with catalytic capacities, similar to cell phospholipases from mammals and plants, are also found in bacteria, and thus, that gives easy access to specific enzymes for practical applications in biocatalysis [40]. Detailed studies of the structure, mechanism and kinetics of phospholipases have been deeply reviewed [41-44]. All the phospholipases with potential applications are hydrolytic enzymes that are often secreted outside the cell. In principle, they are able to catalyze both the hydrolysis and the reverse reaction with the ester bond formation in the presence of the suitable acceptor or donor.

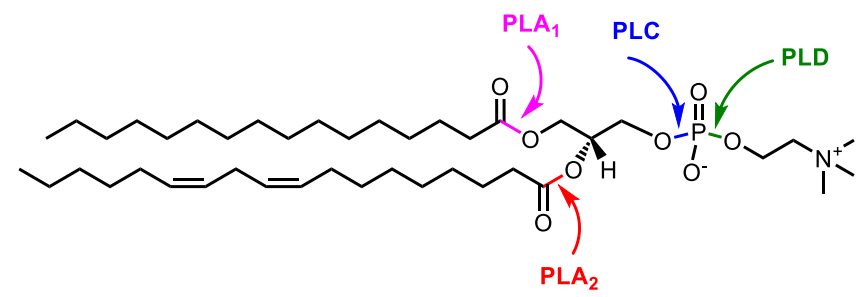

Figure 2. Enzymes acting on phosphatidylcholine (here reported as 1-palmitoyl-2-linoleoylphosphatidylcholine) and their specific site of action.

It should be noted that in recent years, there has been a partial shift in the topics of publications regarding PLD activity; in fact, more attention has been given to the production of molecules with a specific action rather than to the general screening of enzymatic activities. In this review, the authors aimed to build an overview of the preparation of polar head modified PLs describing the main strategies to transform, by PLD-catalyzed transformations, the more abundant natural PL, PC, into these new PLs in order to extend the spectrum of PLs available for applications in basic research as well as in biomedical and biotechnological practice. 


\section{Polar Head Modification}

Polar head modified PLs (PX) find applications in many important fields such as nutraceuticals, prodrugs, liposome technology and cosmetics. Phosphatidylation of bioactive alcohols has been demonstrated, in fact, to be a very suitable strategy in order to stabilize and administer active molecules because the phosphatidyl residue constitutes a nontoxic carrier moiety with a high affinity for cell membranes and a great hydrophobicity which prevents bioactive moiety degradation.

PX can be prepared starting from PC via a PLD-catalyzed transphosphatidylation reaction. All the bioconversions described in this review follow a quite simple and well-established procedure which was already known in the middle of the 1990s and is here presented in Scheme 1 [45].

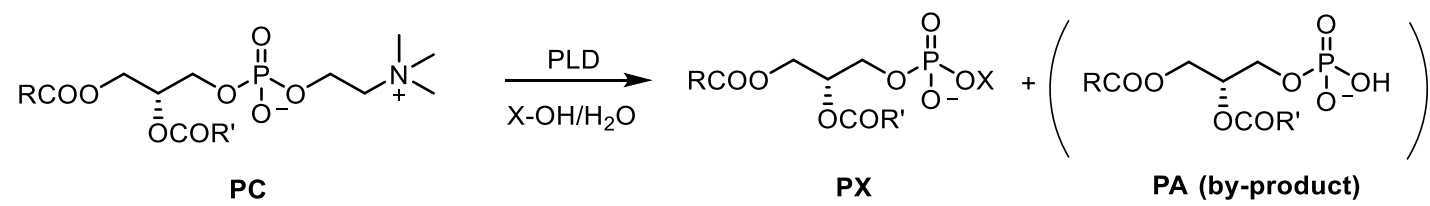

Scheme 1. Reaction scheme of a phospholipase D (PLD)-mediated polar head transphosphatidylation of PC.

The reactions were performed on PC extracted from natural sources as a substrate. PC is one of the main constituents of the so called lecithins provided commercially by the degumming step of edible oils. Crude lecithins contain approximatively PLs and oil spanning in a range of 60 to $30(w / w)$. The principal components of PL fraction are PC, PE, PI and PA, which could be all separated and obtained with a high degree of purity by solvent partitioning and chromatographic steps [46].

The enzymatic approach aiming to modify the polar head of PC, the most abundant natural PL, exploits PLD which is an extracellular hydrolytic enzyme with a broad substrate specificity. PLD occurring in animals, plants and microorganisms catalyzes in vivo the hydrolysis of PC to choline and phosphatidic acid (PA). However, some PLDs from particular sources possess a quite unique property among hydrolytic enzymes which is essential in practical applications such as the preparation of polar head-modified PLs starting from crude or purified PC. In fact, in the presence of appropriate nucleophiles, preferably primary aliphatic alcohols, they show a high transphosphatidylation capacity even in the presence of water $[33,45]$. When the bioconversion is conducted in the presence of an appropriate acceptor (an alcohol), transphosphatidylation can occur in vitro with different ratios between PA and the new polar head bearing PX, depending on the nature and concentration of the alcohol, as well as on the enzymatic source and on the overall experimental conditions $[47,48]$. In the past 30 years, a great number of strains of PLD have been studied, and this bioconversion has been exploited in different protocols to produce a wide variety of new products with very different applications [49,50]. However, an exact evaluation of different PLDs is difficult to illustrate because the enzyme source, the alcohol used as nucleophile, the solvent system and the reaction parameters prove to be strongly interdependent. Nevertheless, the availability of enzymes with a wide substrate specificity and high transfer capacity has offered very convenient access to natural and synthetic polar head modified PLs.

The application of PLDs from bacterial sources has allowed the highly selective transfer of a nucleophilic component (alcohol) in a water medium to PC with the formation of a new PL and PA in different ratios [51]. In particular, different bacterial sources of PLD provided very powerful enzymes with very different transphosphatidylation potential. In 1994, D'Arrigo et al. identified three Streptomyces species-PMF, PM43, PMR—as microorganism producers of very particular PLDs which were applied for the transformation of the most abundant natural PL, PC, from soy beans into other minor natural products (PX), namely phosphatidylserine (PS), PE and phosphatidylglycerol (PG) and also in a great number of unnatural compounds [52,53]. The reactions were usually carried out in water-organic solvent mixtures, and the extent of the competing hydrolytic reaction depended on the nature of the nucleophile and the reaction conditions. The presence of water in the reaction medium 
always caused the formation of the PA as a byproduct of the transphosphatidylation process, lowering reaction yields and forcing the need to perform further purification steps. The purification of this class of compounds was not straightforward and required different chromatographic and selective precipitation steps. Thus, from a synthetic point of view, the possibility to enhance the selectivity of the reaction could allow to simplify the preparation of these compounds on a relatively larger scale leading to lower production costs.

\subsection{Natural PLS}

\subsubsection{Phosphatidylserine}

Phosphatidylserine (PS, PX-1) has achieved a great commercial interest for a long time as it is a membrane PL ubiquitously present in all cellular membranes, especially in the brain, and is involved in many neurological processes [30]. It is a molecule that presents many nutritional and medical functions as low levels of PS is linked to memory problems, to Alzheimer's and other mental diseases. It is demonstrated that the assumption of PS leads to positive benefits in terms of mind and memory enhancement. It reduces the age-related decline in mental function, it prevents Alzheimer's and dementia, it is considered a mood enhancer to cure depression, it improves athletic performance, it is a stress reducer and it is an important ingredient of liposomes used in drug delivery [54]. The main drawback is linked to its low availability in nature and high costs of extraction from natural sources [42].

The most common method described by different authors in the 1990s was the synthesis of PS by using different PLD solutions (from Streptomyces PMF, cabbage, Streptomyces prunicolor) in biphasic reaction mixtures (as shown in Scheme 2) [33,55]. The best results were obtained with the PLD solution from Streptomyces sp. In detail, a mixture of enzymatic solution with $0.2 \mathrm{M}$ phosphate buffer at $\mathrm{pH} 5.6$ containing 3.4 M L-serine and $\mathrm{CaCl}_{2}$ was added to an initial solution of PC $17.8 \mathrm{M}$ in ethyl acetate. The main drawback of the traditional systems was, as usual, the concomitant formation of PA with the desired PS and the necessary purification steps.

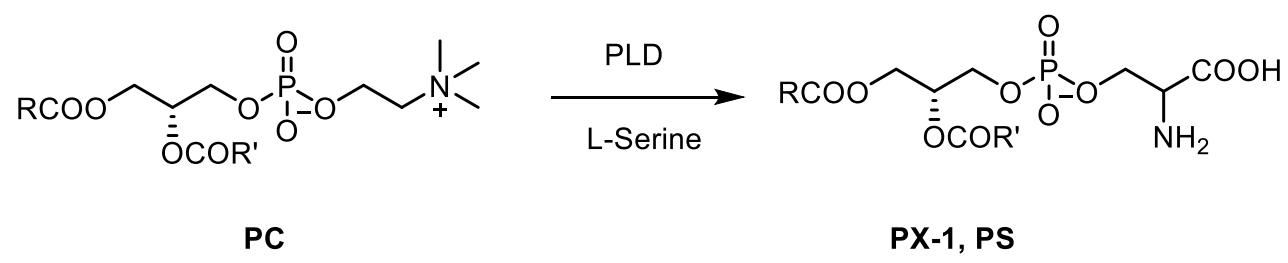

Scheme 2. Schematic equation of the synthesis of phosphatidyserine (PX-1).

The modification and the improvements of the reaction conditions for the synthesis of PS have been the object of many studies taking advantage of new strategies in the biocatalytic field. In particular, the screening of the use of a great number of novel eco-friendly solvents such as ionic liquids (ILs); deep eutectic solvents (DES); biobased solvents such as $\gamma$-valerolactone, limonene and p-cymene was performed. On this topic, in 2012, D'Arrigo et al. started to investigate for the first time the possibility to switch PLD-catalyzed reactions from water to a nonaqueous green system [56]. Their work aimed to use the IL [BMIM] $\left[\mathrm{PF}_{6}\right]$ as an alternative solvent to perform the PLD-mediated enzymatic conversion in order to obtain the modification of the enzyme selectivity with the suppression of unwanted hydrolytic side reactions, leading to an easier product recovery by a simple solvent extraction. The reduction or absence in water leads, in fact, to the absence of the competitive hydrolysis reaction making the product purification much easier and cheaper due to the limited use of organic solvents, because the purification steps could be performed without very long chromatographic separations. The bioconversion was performed by dissolving, at first, $\mathrm{PC}$ in toluene at $40^{\circ} \mathrm{C}$. A mixture of IL/0.1 M sodium acetate buffer (90/10) at $\mathrm{pH} 5.6$ containing $3 \mathrm{M}$ of L-serine and $\mathrm{CaCl}_{2} 0.1 \mathrm{M}$ was added to the solution of PC under magnetic stirring. PLD from Streptomyces PMF was then added, and the bioconversion was stirred for 
$24 \mathrm{~h}$ at $40{ }^{\circ} \mathrm{C}$, yielding $91.4 \%$ of PS with a complete suppression of unwanted hydrolytic side reaction, which resulted in an easier final product purification.

In the same period, Duan et al. developed the reactions in two other reaction systems to prepare PS without the formation of PA with an overall yield over $90 \%$ using $\gamma$-valerolactone in 2012 [57] and 2-methyltetrahydrofuran in 2013 [58]. The undesired hydrolytic side reaction problem was also addressed by Chen et al. in 2013, who developed the conditions to perform the PLD transphosphatidylation of PC in a microaqueous water-immiscible organic solvent in order to prevent undesired hydrolysis of PLs [59]. The bioconversion was conducted with PLD from Streptomyces racemochromogenes at $30^{\circ} \mathrm{C}$ for $8 \mathrm{~h}$, with an L-serine to PL ratio of $20: 1$, the solvent system contained $6 \%$ of water in butyl acetate. This bioconversion yielded $88 \%$ of the desired product reaching a moderately complete suppression of the undesirable hydrolysis.

More recently, Yang et al. [60] described the use of deep eutectic solvents (DES) as an alternative inexpensive, environmentally friendly, enzyme compatible solvent to conduct the PS synthesis. Different types of DES were tested, as a general procedure, the bioconversion was carried out in a batch reactor at $40{ }^{\circ} \mathrm{C}$, the reaction mixture was composed of PC, DES, L-serine, PLD and water $(0.5 \%)$. The reaction was conducted using choline chloride/ethylene glycol as DES gave the best results yielding PS over $90 \%$.

Very recently, Qin et al. performed the synthesis of PS in the eco-friendly and green solvent, cyclopentyl methyl ether, using a recombinant PLD from Streptomyces chromofuscus expressed in Escherichia coli which allowed a yield of $84.4 \%$ of conversion of PC in a scale-up production of $1 \mathrm{~L}$ volume to be reached [61].

\subsubsection{Phosphatidylglycerol and Cardiolipin}

Phosphatidylglycerol (PG, PX-2) is one of the most abundant PLs found in natural membranes. It possesses an excellent liposome forming ability and has been studied from a long time-since 1985-as an emulsifier for drug delivery systems [62-64]. In fact, PG is known to have unique surfactant/lubricant properties, particularly when mixed with appropriate proteins. It has been found, for example, in relatively large amounts in mammalian lungs compared to other mammalian membranes pushing the research on the development of surfactant preparations for therapeutic practices for the relief of a variety of diseases such as neonatal respiratory distress syndrome [65]. Although PG is a naturally occurring PL, it is found only in a small amount in nature, and its enzymatic preparation has been performed by different groups [66]. For example, Piazza et al. demonstrated that with PLD from Streptomyces sp., PG was obtained in a nearly quantitative yield when the molar ratio of glycerol to PC was at least 5 to 3 showing that this PLD had a higher selectivity for glycerol than in cabbage PLD [67]. Moreover, during the preparation of PG catalyzed by PLD from Streptomyces sp. (as shown in Scheme 3), D'Arrigo et al., in 1996 [68], observed that the prepared PG under appropriate conditions could be transformed into diphosphatidyglycerol (cardiolipin, CLP, PX-3) [69]. This molecule is an acidic lipoprotein that is abundant in the inner mitochondrial membrane and is required for normal respiratory chain enzymic activity [70]. It is particularly abundant in the mammalian heart. It is also known to be the essential lipid of the antigen in the serodiagnosis of syphilis. The synthesis was performed starting from PC dissolved in dichloromethane, which was treated with PLD in sodium acetate buffer $0.1 \mathrm{M}$ at pH 5.6 with $\mathrm{CaCl}_{2} 0.1 \mathrm{M}$ containing an excess of glycerol $(8 \mathrm{M})$. The bioconversion was left stirring at $200 \mathrm{rpm}$ at $25^{\circ} \mathrm{C}$ for $7 \mathrm{~h}$, yielding PG in high yields. The obtained PG was dissolved in $\mathrm{CH}_{2} \mathrm{Cl}_{2}$ and treated again with fresh PLD in the same buffer. This mixture was left stirring for $24 \mathrm{~h}$ at $37^{\circ} \mathrm{C}$. Then, the biphasic mixture was allowed to separate in order to withdraw the aqueous phase and replaced with a fresh enzymatic solution with a complete conversion in PX-3 after 5 days. 


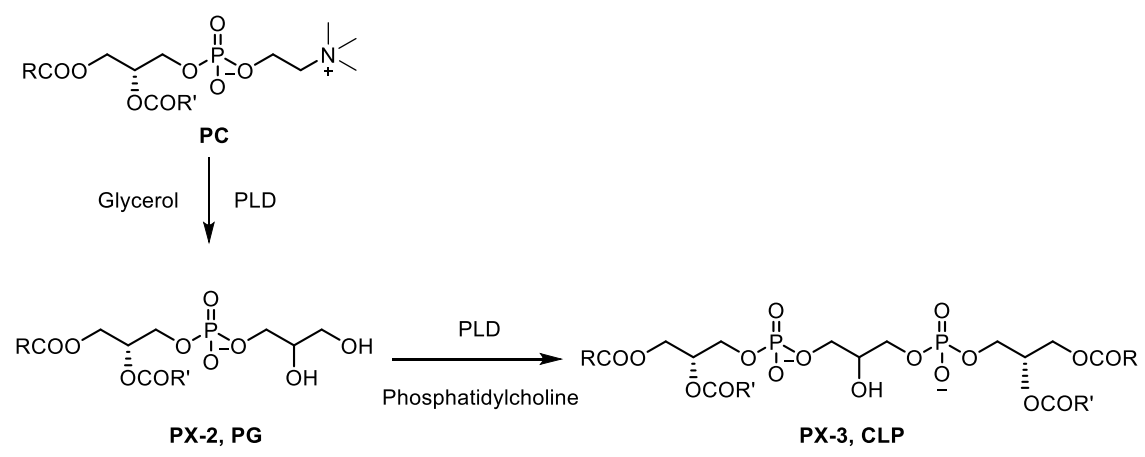

Scheme 3. Schematic equation of the synthesis of phosphatidylglycerol (PX-2) and cardiolipin (PX-3).

\subsubsection{Phosphatidylethanolamine}

Phosphatidylethanolamine (PE, PX-4) is another major PL in the membranes of eukaryotic cells. The importance of PE metabolism in mammalian health has recently emerged following its association with Alzheimer's, Parkinson's and nonalcoholic liver diseases, as well as with the virulence of certain pathogenic organisms [71,72]. Moreover, PE has a significant influence on the heart to prevent cell damage. This product also presents good antioxidant activity against free radicals, which is another characteristic which could provide beneficial effects to human health.

The production of PE from natural sources by solvent extraction constitutes the main strategy to recover it even if the purity of PE does not always fit industrial requirements. Chromatographic methods allowed the obtainment of more purified PE samples even if they required high volumes of organic solvents and multistep procedures [73]. PLD-catalyzed transformations of natural PC represents the best way to prepare PE in high purity (see Scheme 4).

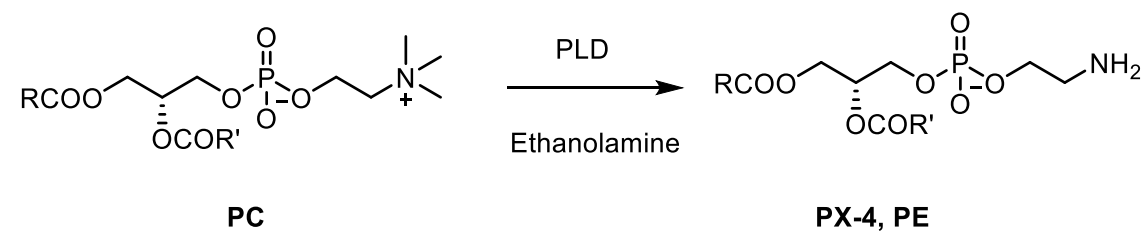

Scheme 4. Schematic equation of the synthesis of phosphatidylethanolamine (PX-4, PE).

The first results were published by Juneja et al. in 1988; they conducted the transphosphatidylation of PC to PE by testing seven different sources of phospholipase D, one of which was obtained from cabbage, whilst the others were all obtained from Streptomyces sp. All the bioconversions were performed at $30^{\circ} \mathrm{C}$ for $1 \mathrm{~h}$ in a biphasic system composed of ethyl acetate and a buffer containing the enzyme. Different parameters such as the type of buffer (concentration and $\mathrm{pH}$ ), and the concentration of PC, ethanolamine and $\mathrm{CaCl}_{2}$, were tested. The best observed conditions in terms of reaction selectivity around $100 \%$ were obtained, on one hand, with PLD from Streptomyces sp. and ethanolamine $4.9 \mathrm{M}$, and on the other hand, with PLD from cabbage with ethanolamine $2 \mathrm{M}$ [74].

D'Arrigo et al. prepared PE from PC in a biphasic system (ethyl acetate/ $\mathrm{NaAcO}$ buffer $0.1 \mathrm{M} \mathrm{pH}$ 5.6, 0.1 $\mathrm{M} \mathrm{CaCl}_{2}, 1 \mathrm{M}$ ethanolamine) with PLD from Streptomyces PMF and PM43 with a very high selectivity ( $\mathrm{PE} / \mathrm{PA}=23$ and 22, respectively) and yield (96\% and $92 \%$, respectively) at $37^{\circ} \mathrm{C}$ in $3 \mathrm{~h} \mathrm{[53]}$.

Dippe et al. performed the enzymatic transphospatidylation of 1,2-dioleoyl-sn-glycerophosphocholine with N- or C2-substituted derivatives of ethanolamine (diethanolamine, triethanolamine, serinol, Tris, Bistris), by testing two different PLDs from Streptomyces sp. and cabbage, aiming to produce a series of ethanolamine derivatives with identical charge but with different volumes with an interest in biotechnological practices [75]. The production of these new PLs was performed in a two phase system consisting of NaOAc buffer $300 \mathrm{mM}$ at pH 5.6 containing $120 \mathrm{mM}$ of $\mathrm{CaCl}_{2}$ and $2.8 \mathrm{mM}$ of the acceptor alcohol and diethyl ether to which the enzyme was added. These bioconversions were conducted at 
$30{ }^{\circ} \mathrm{C}$, shaken at $400 \mathrm{rpm}$ for $5 \mathrm{~h}$ in the case of the PLD from Streptomyces sp. and $8 \mathrm{~h}$ in the case of PLD from cabbage.

\subsection{Synthetic PLS}

The synthetic PLs, which will be described in this section, are summarized in Table 1. The PLD source and the reaction time as well as its main application is also reported in Table 1.

Table 1. Synthetic phospholipids (PLs) with essential preparation parameters (PLD source, incubation time, yield) and their main applications.

\begin{tabular}{ccccc}
\hline Compound & PLD Source & Incubation Time (h) & Yield (\%) & Application \\
\hline PX-5 & Streptomyces lydicus & 24 & 90 & Antioxidant \\
PX-6 & Streptomyces lydicus & 2 & 94 & Antioxidant \\
PX-7 & Streptomyces sp. & 4 & 18 & Tyrosinase inhibitor \\
PX-8 & Streptomyces sp. & 3 & 60 & Tyrosinase inhibitor \\
PX-9 & Streptomyces sp. & 3 & 61 & Cytotoxic compound \\
PX-10 & Streptomyces sp. & 24 & 90 & Antibacterial \\
$\mathbf{P X - 1 1}$ & Streptomyces sp. & 24 & 73 & Antibacterial \\
$\mathbf{P X - 1 2}$ & Streptomyces sp. & 24 & 54 & Antibacterial \\
$\mathbf{P X - 1 3}$ & Streptomyces sp. & 24 & 17 & Antibacterial \\
$\mathbf{P X - 1 4}$ & Actinamadure sp. & 24 & 97 & Intracellular antioxidant \\
$\mathbf{P X - 1 5}$ & Streptomyces sp. & 2 & 95 & Preparation of anionic liposomes \\
$\mathbf{P X - 1 6}$ & Streptomyces sp. & 2 & 67 & Preparation of anionic liposomes \\
$\mathbf{P X - 1 7}$ & Streptomyces sp. & 2 & 23 & Preparation of anionic liposomes \\
$\mathbf{P X - 1 8}$ & Streptomyces sp. & 22 & 12.5 & Important compound in different \\
$\mathbf{P X - 2 0}$ & Actinamadure sp. & 48 & 87 & human organs \\
$\mathbf{P X - 2 1}$ & Streptomyces sp. & 12 & 94 & Preparation of new liposomes \\
$\mathbf{P X - 2 2}$ & Streptomyces sp. & 24 & 96 & Anesthetic and sedative \\
\end{tabular}

\subsubsection{6-Phosphatidyl-L-Ascorbic Acid}

Nagao et al. worked, in early times (1991), on the cellular defense system against oxygen toxicity and especially against membrane lipid peroxidation [76]. The membrane defense against oxygen radicals, which occurs at the interface between the aqueous phase and the membrane lipids, is considerably important. The idea of the authors was to prepare a new PL with antioxidant activity bearing an appropriate antioxidant residue as a polar head; 6-phosphatidyl-L-ascorbic acid (PX-5) was selected because L-ascorbic acid is among the important antioxidants in the cellular defense against oxygen radicals, as well presenting a primary hydroxyl group available for PLD catalysed transphosphatidylation. The bioconversion was performed in a biphasic system, where diethyl ether was selected to be the best organic solvent as it reduced the collateral production of phosphatidic acid (as shown Scheme 5). The reaction mixture contained a solution of PC from egg yolk $10 \mathrm{mM}$ in diethyl ether, $2 \mathrm{M}$ L-ascorbic acid adjusted to $\mathrm{pH} 4.5$ with $\mathrm{KOH}$ and a PLD solution from Streptomyces lydicus in sodium acetate buffer $10 \mathrm{mM}, \mathrm{pH}$ 5.1. The mixture was left shaking at $37^{\circ} \mathrm{C}$ for $24 \mathrm{~h}$ to obtain a PC conversion of $90 \%$.

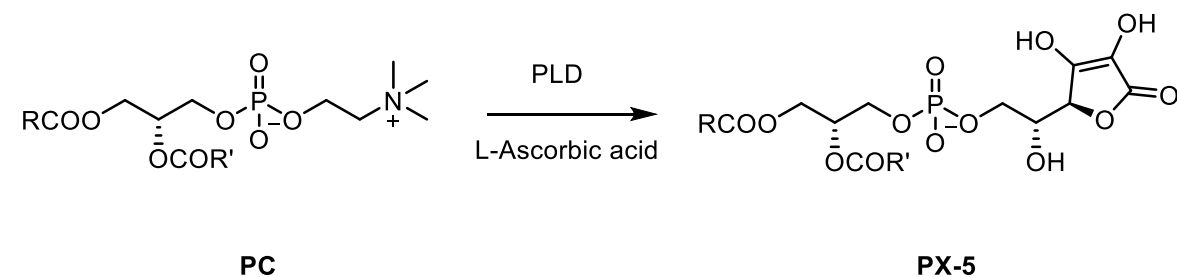

Scheme 5. Schematic equation of the synthesis of 6-Phosphatidyl-L-Ascorbic Acid (PX-5).

\subsubsection{Cyclic Hydroxylated Polar Head Phospholipids}

For many years, the use of PLD for the preparation of new synthetic PLs has been a widely studied topic. However, most of the literature found before 2010 reports the screening and optimization of the 
PLD activity on a great number of potential substrates without evaluating the real applications of the obtained product. The unique exceptions were the molecules reported in Scheme 6, which bore a cyclic hydroxylated polar head and were reported in 1994 by the groups of Koga and Takami for specific uses.

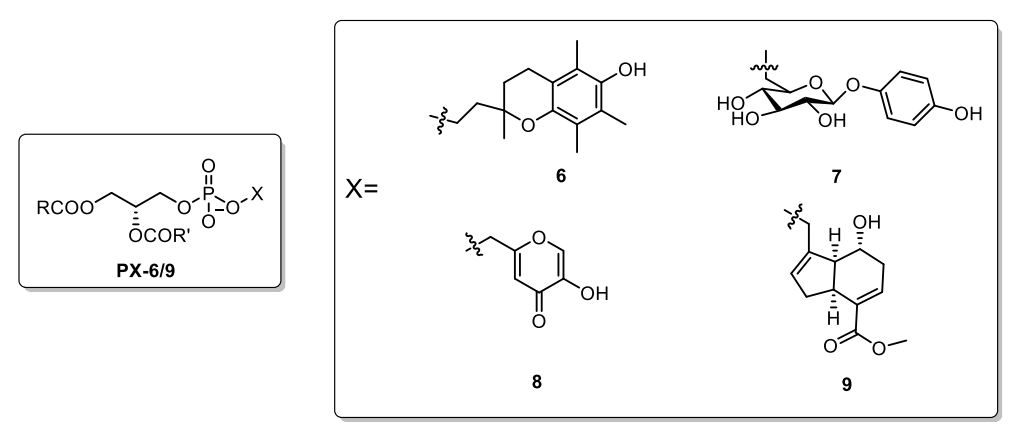

Scheme 6. Synthetic PLs (PX-6/9) presenting a targeted application.

Compound PX-6 (1,2-diacyl-sn-glycero-3-phospho-2'-hydroxyethyl-2', 5' ,7', , $8^{\prime}$-tetramethyl-6' hydroxychroman, named also phosphatidylchromanol) was synthesized in 1994 by Koga et al. by using PLD from Streptomyces lydicus, and the product obtained presented a very good antioxidant activity against lipid peroxidation in PL membranes [77]. PX-6 was prepared from egg yolk PC dissolved in diethyl ether with 2,5,7,8-tetramethyl-6-hydroxy-2-(hydroxyethyl)chroman; this solution was added to PLD previously dissolved in $10 \mathrm{mM}$ acetate buffer at $\mathrm{pH} 5.1$ with $10 \mathrm{mM} \mathrm{CaCl}_{2}$. The incubation was performed at $37^{\circ} \mathrm{C}$ for $2 \mathrm{~h}$, and the desired product was obtained with a $94 \%$ yield.

Compounds PX-7 (1,2-dipalmitoyl-3-sn-phosphatidylarbutin) and PX-8 (1,2-dipalmitoyl-3sn-phosphatidylkojic acid) were produced in the same year by Takami et al. by using PLD from Streptomyces sp. These compounds were demonstrated to be tyrosinase inhibitors in the same manner as the polar heads arbutin and kojic acid, which unfortunately were water-soluble and instable for cosmetic use. Their derivatization in PX-7 and PX-8, respectively, allowed their action in cosmetics and pharmaceuticals to be tested in order to prevent overproduction of melanin in epidermal cells by inhibiting tyrosinase activity [78]. PX-7 was prepared by mixing 1,2-Dipalmitoyl-sn-glycero-3-phosphocholine (DPPC) with arbutin in a biphasic system composed of ethyl acetate and sodium acetate buffer $0.2 \mathrm{M}$ at pH 5.6 with $4 \%$ of $\mathrm{CaCl}_{2}$ containing PLD. After having stirred the reaction at $35{ }^{\circ} \mathrm{C}$ for $4 \mathrm{~h}$, the desired product was obtained with an $18 \%$ yield, and the undesired PA was obtained with a $48 \%$ yield. In the case of product PX-8, the reaction conditions were slightly modified; the initial DPPC was mixed with kojic acid and still treated with PLD, but in this case, the biphasic mixture was composed of diethyl ether and sodium acetate buffer $0.2 \mathrm{M}$ without $\mathrm{CaCl}_{2}$. The reaction was performed for $3 \mathrm{~h}$, and the desired product was obtained with a $60 \%$ yield with a much lower production of PA (9\%).

Compound PX-9, phosphatidylgenipin, still studied by Takami et al. by using PLD from Streptomyces sp. presented a very high cytotoxic action against Hela cells, human embryonic lung fibroblast and MT-4 cells [79]. The insertion of genipin into the phosphatidyl backbone deeply enhanced its cytotoxicity towards the three cell lines because it represented a very good carrier into cells. For the preparation of PX-9, DPPC was incubated with genipin in a biphasic mixture composed of ethyl acetate and sodium acetate buffer $0.2 \mathrm{mM}$ at $\mathrm{pH} 5.4$ with $4 \%$ of $\mathrm{CaCl}_{2}$ and PLD. After $3 \mathrm{~h}$ of incubation at $35{ }^{\circ} \mathrm{C}$ under stirring, the product was obtained with a yield of $61 \%$.

\subsubsection{Phosphatidylated Terpenes}

In 2008, Yamamoto et al. investigated the transphosphatidylation of PC with terpenes in order to introduce functional terpenes into PLs for food and cosmetic applications (as shown in Scheme 7). They prepared new phosphatidylated monoterpenes containing geraniol (PX-10), geranylgeraniol (PX-11), phytol (PX-12) and farnesol (PX-13) which were known to show a markedly antibacterial 
activity and an antiproliferative effect on human cancer cells [80]. The aim was to exploit these peculiar characteristics and use them for industrial applications in the food and cosmetic industries. Different bioconversion conditions were studied, the reactions were carried out both in biphasic systems containing ethyl acetate/water or directly in water without organic solvents. Different PLDs were tested, deriving from Streptomyces sp., Streptomyces chromofuscus, cabbage and peanut. The bioconversions were conducted, at first, by dissolving PC and the terpene in ethyl acetate followed by the addition of PLD in buffer containing $\mathrm{CaCl}_{2}$ and albumin. For the PLDs deriving from cabbage and peanut, the buffer was sodium acetate $0.2 \mathrm{M}$ at $\mathrm{pH}$ 5.6; for the other two PLDs, the buffer was Tris- $\mathrm{HCl}$ at $\mathrm{pH}$ 8. The reactions were conducted at $37^{\circ} \mathrm{C}, 350-400 \mathrm{rpm}$ in the dark for $24 \mathrm{~h}$. Only the PLD from Streptomyces sp. revealed to be a suitable enzyme for terpene-PL synthesis, the yield of which decreased with the chain length of the terpene used going from $90 \%$ for PX-10 to 17\% for PX-13.

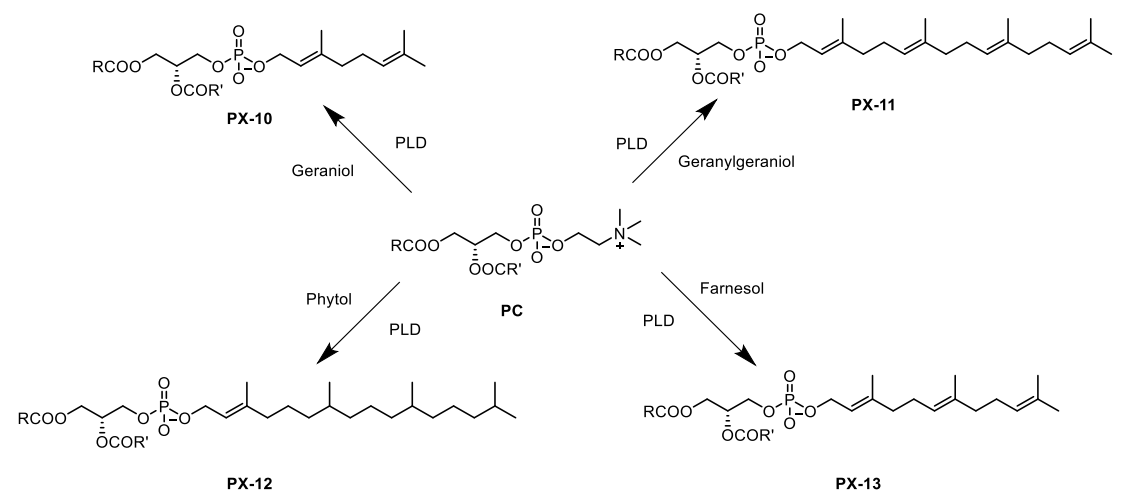

Scheme 7. Schematic equation of the terpenes—phosphatidylderivatives (PX-10/13).

\subsubsection{Phosphatidyltyrosol}

More recently, in 2013, with the same goal of the previous work reported in Section 2.2.3, of improving the intracellular antioxidant defense systems, Victor Casado et al. decided to introduce the tyrosol residue in the PLs polar head; in fact, tyrosol was known to exert powerful protective effects against oxidative injuries in cell systems [81,82]. Authors pointed out that the effectiveness of tyrosol in some biological systems was related to its capability to penetrate the cells. Then, they studied the production and scale-up of phosphatidyltyrosol (PX-14) aiming to exploit the known antioxidative effect of tyrosol, in particular, by augmenting its effectiveness through lipophilization which enhanced its solubility and capability of penetrating cells.

This bioconversion, reported in Scheme 8, was performed using a food grade PLD from Actinamadure sp. in a GRAS (Generally Recognized as Safe) biphasic reaction medium composed of an aqueous phase and ethyl butyrate $(1: 2 v / v)$. The aqueous phase consisted of a sodium acetate buffer $0.2 \mathrm{M} \mathrm{pH} 5.6,208 \mathrm{mM}$ of tyrosol, $67 \mathrm{mM} \mathrm{CaCl}_{2}$, and the bioconversion was conducted at $40{ }^{\circ} \mathrm{C}$ and $200 \mathrm{rpm}$. The studied process was also scaled-up in a $1 \mathrm{~L}$ thermostated stainless steel reactor containing $660 \mathrm{~g}$ of reaction mixture under $\mathrm{N}_{2}$ to avoid oxidation, allowing the obtainment of the highly purified desired product PX-14 with a 97\% yield in mass.

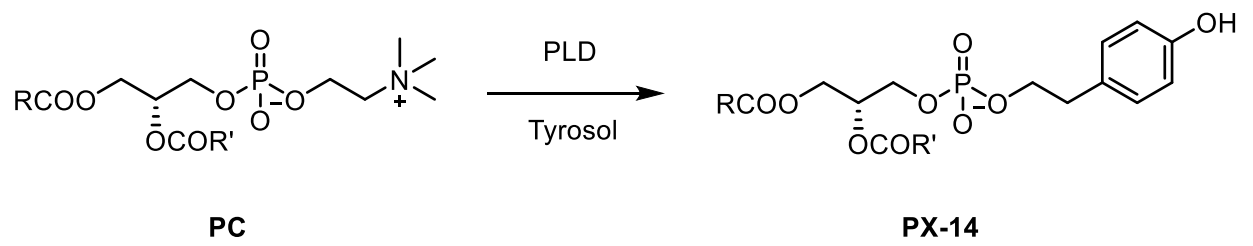

Scheme 8. Schematic equation of the synthesis of phosphatidyltyrosol (PX-14). 


\subsubsection{Phosphatidyl Saccharides}

Another interesting application of new PLs was studied by Song et al. in 2013; they prepared phosphatidyl saccharides (PX-15 to PX-17) -reported in Scheme 9-for the preparation of anionic nanoliposomes with enhanced stability [83]. They studied the correlation between enzymatically conjugated mono-, di- and trisaccharides and the phosphatidyl group with their stability against dehydration/rehydration processes. Liposomial vesicles have always been considered very useful tools in the delivery of drugs, nutrients or genes; however, the limited use of PC as a primary constituent of new liposomes is linked to its low stability [84]. The conjugation of the phosphatidyl group with different sugar moieties with an increasing bulky structure appeared to be the solution that would allow the use of PC as a building block as it is stabilized by the presence of the saccharides. The synthesis of these new PLs was performed in a biphasic medium, where PC was dissolved in ethyl acetate, whilst PLD from Streptomyces sp. was dissolved in sodium acetate buffer adjusted to $\mathrm{pH}$ 5.6. This buffer was then added to the reactor containing glucose/sucrose/raffinose and stirred for $10 \mathrm{~min}$ before the addition of the PC solution. The reaction was left at $200 \mathrm{rpm}$ at $50^{\circ} \mathrm{C}$ for $2 \mathrm{~h}$, then quenched by the addition of chloroform. The yields of the different PLs depended on the steric hindrance of the alcohols: PX-15 was obtained with a 95\% yield, PX-16 with $67 \%$ and PX-17 with a $23 \%$ yield. These new PLs presented a higher negative surface charge and were smaller in size compared to PC nanoliposomes. The enhanced stabilizing effect, showed by these nanoliposomes based on the phosphatidyl saccharides PX-15/16, prevented the aggregation and fusion during storage. This was due to the presence of many $\mathrm{OH}$ functionalities which resulted in a higher electrostatic repulsive force and a higher formation of H-bonds, whilst the increasing amount of sugar rings from glucose to raffinose incremented the critical micelle concentration (CMC). The results proved that the compounds PX-14/16 could form nanoliposomes without the further addition of stabilizing excipients, and they could be used for the preparation of noncytotoxic and serum stable delivery systems.

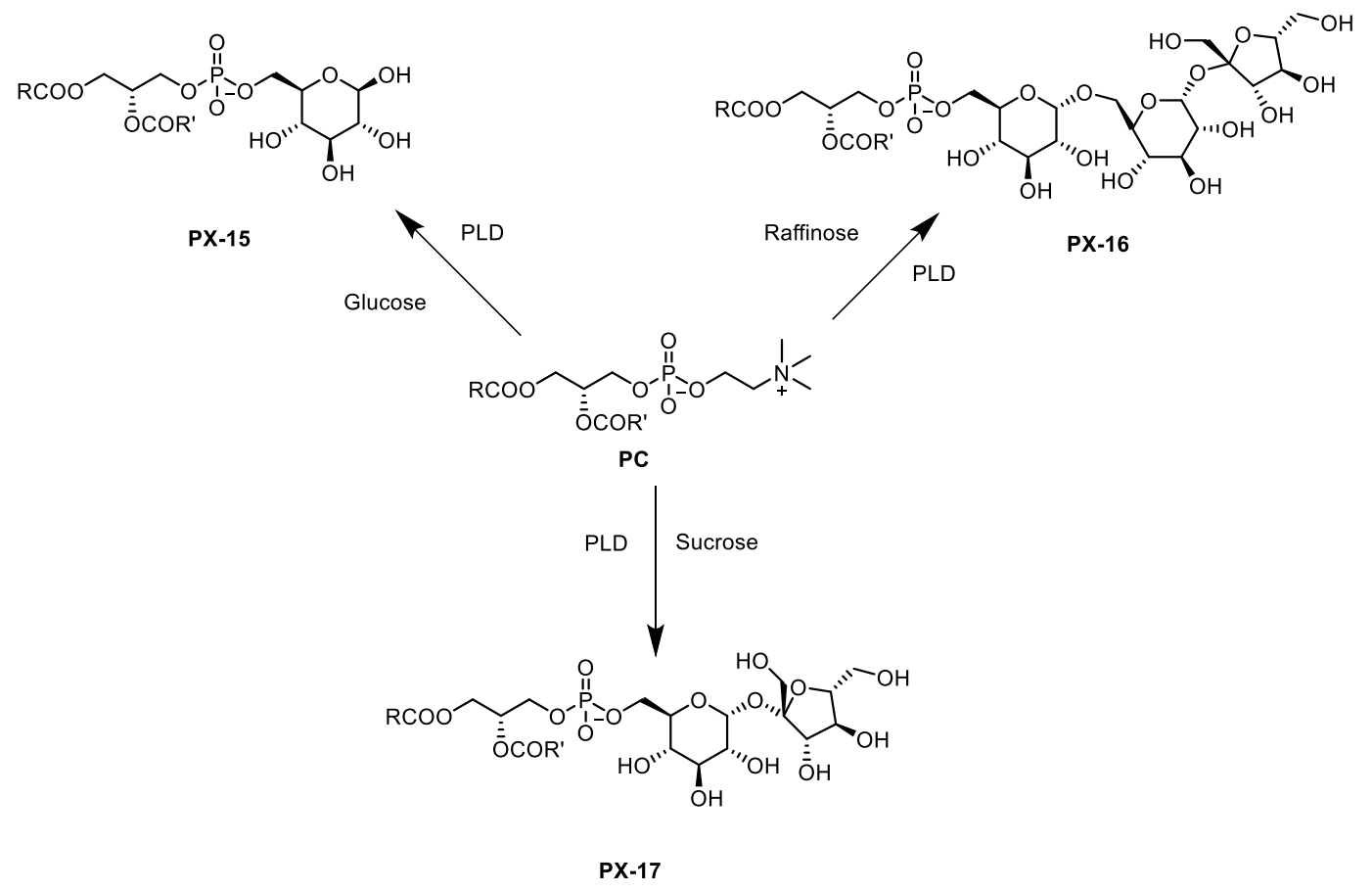

Scheme 9. Schematic equation of the saccharides-phosphatidylderivatives (PX-15/17).

\subsubsection{1-Phosphatidyl- $\beta$-D-glucose}

1-Phosphatidyl- $\beta$-D-glucose (1-PGlc, PX-18) is a PL which has been discovered in red blood cells of the human umbilical cord and is found in epithelial cells of various human organs, in human neutrophils and in the subventricular zone of the adult mouse brains [85]. In order to study thoroughly 
the function of this compound, a preparation method was required since the amount of lipid obtained from natural sources was very limited. However, the transphosphatidylation with wild type-PLD from Streptomyces PMF allowed the preparation of 6-phosphatidyl- $\beta$-D-glucose (PX-19) which is the isomer of PX-18, as reported by D'Arrigo et al., because of the higher reaction rate of the primary hydroxyl group of - $\beta$-D-glucose (as shown in Scheme 10) [33]. Therefore, more recently, in 2016, Inoue et al. proposed the use of an engineered enzyme for the same reaction constituted by a variant of PLD from Streptomyces 187K/191W/385Y (KWY) [86]. In detail, the optimized protocol was performed by dissolving PC in ethyl acetate and mixing it with a saturated solution of $\mathrm{NaCl}$ and $50 \mathrm{mM}$ glycylglycine- $\mathrm{NaOH}$ buffer at pH 7.5 containing KWY-PLD and glucose. The reaction was left shaking for $22 \mathrm{~h}$ at $20^{\circ} \mathrm{C}$ in order to produce the desired product PX-18, which was obtained with a final yield of $12.5 \%$ due to the formation of undesired positional isomers as byproducts.

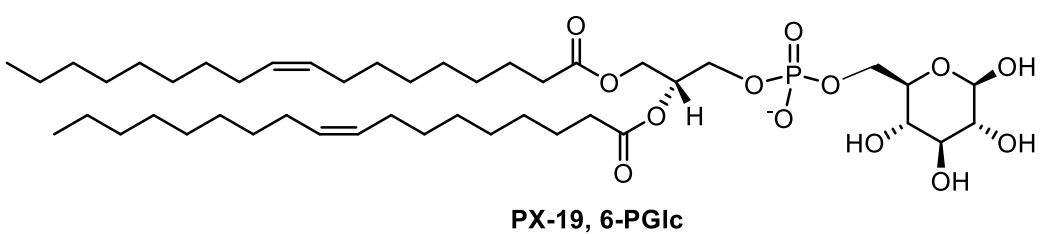

PX-19, 6-PGIC<smiles>OC[C@H]1OC(O)[C@H](O)[C@H](O)[C@H]1O</smiles><smiles>[2H][C@@H](COC(=O)CCCCCCCCCCC/C=C\CCCCCCCCCCCC)COP(=O)(O)OCC[N+](C)(C)C</smiles>

PC<smiles>O=[13C]([O-])O[C@@H]1[C@@H](O)[C@H](O)[C@@H](O)O[C@@H]1CO</smiles>

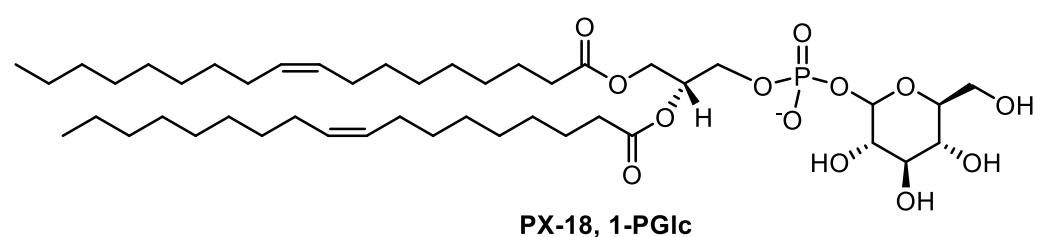

Scheme 10. Schematic equation of the synthesis of 1-phosphatidylglucose (1-PGlc, 1,2-dioleoylphosphatidyl-1-glucose, PX-18) and 6-phosphatidylglucose (6-PGlc, 1,2-dioleoyl-phosphatidyl6-glucose PX-19).

\subsubsection{Phosphatidyl-Batyl Alcohol}

In 2017, Arranz-Martinez et al. studied the enzymatic transphosphatidylation between PC and batyl alcohol to produce a novel PL-glyceryl ether, phosphatidyl-batyl alcohol (PBA, PX-20, see Scheme 11) with the purpose of obtaining new liposomes [87]. In order to optimize the bioconversion, the authors investigated the following parameters: the type of organic phases (in particular the use of GRAS organic solvents), the different ratios between aqueous and organic phase, the amount of calcium chloride, the reaction temperature, the percentage of PLD and the molar concentration of the reactants. This study presented a very promising tool that could be applied for the synthesis of highly 
valuable ingredients, which can potentially be used as bioactive lipids or as drug delivery vessels. The best results, which allowed the obtainment of $70 \%$ of PX-20, was performed by using $5 \%(w / w)$ of PLD, an equimolar ratio of reactants and limonene/acetate buffer with a volumetric ratio of 1:3. This process was optimized and scaled up allowing the obtainment of similar results in terms of yield and composition. The concentration of both substrates in the reaction mixture was $126 \mathrm{mmol} / \mathrm{L}$, and the ratio of organic phase (limonene)/sodium acetate buffer $0.1 \mathrm{M}$ at $\mathrm{pH} 5.5$ was $1 / 3$. The incubation was performed at $50{ }^{\circ} \mathrm{C}$ for $48 \mathrm{~h}$ in the presence of $67 \mathrm{mM} \mathrm{CaCl}_{2}$. After centrifugation, this allowed the obtainment of two liquid phases and a solid one; the solid interface was washed twice with organic solvent and three times with distilled water before being centrifuged again. The solid phase was then freeze-dried in order to obtain a solid residue. With this procedure, the desired product PX-20 was obtained ( $87 \%$ yield) with a purity higher than $70 \%$, which allowed it to be tested as a bioactive lipid.
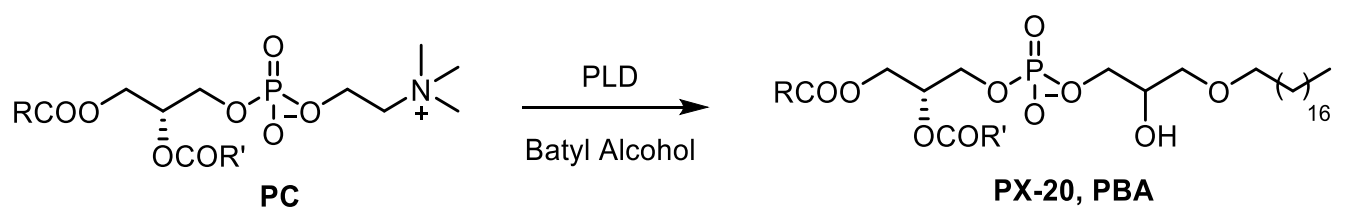

Scheme 11. Schematic equation of the synthesis of phosphatidyl-batyl alcohol (PBA, PX-20).

\subsubsection{Phosphatidylhydroxybutyrate}

Very recently, in 2019, Li et al. described the preparation of a novel PL, phosphatidylhydroxybutyrate (PB, PX-21), for the application in the field of anesthetic and sedatives [88]. The new PL, was prepared by transphosphatidylation of PC with sodium $\gamma$-hydroxybutyrate (NaGHB, as shown in Scheme 12). $\mathrm{NaGHB}$ is a naturally occurring neurotransmitter produced by the central nervous system metabolism and has many applications in the medical field being a psychoactive molecule. GHB is an anesthetic and hypnotic agent that enables patients to physiological sleep. It is employed to treat symptoms of alcohol dependence and opiate withdrawal syndrome. Moreover, it is also employed as an adjuvant for diseases such as Parkinson's and Alzheimer's. However, NaGHB being a hydrophilic and small molecule has difficulties to pass the blood-brain barrier in order to act on the central nervous system and is rapidly metabolized. For those reasons, high dosages of NaGHB should be used in order to be active, with many adverse side effects. For that reason, the authors decided to attach the NaGHB as the polar head of a new PL aiming to decrease the hydrophilicity of the drug, to increase the solubility in lipids and, therefore, obtain an improvement of the mobility through cell membranes. It was noticed that after the absorption into the human brain of PX-21, the widely present PLD hydrolyzed the polar head and released the drug in loco. Two general synthesis procedures were studied, one using an aqueous-solid system and one a liquid-liquid system. The aqueous-solid procedure started with the dissolution by ultrasounds of PC in ethylacetate, followed by the addition of nanoscale silicon dioxide and acetone, and the mixture was left shaking at $400 \mathrm{rpm}$ for $3 \mathrm{~h}$ at room temperature. This procedure was performed to absorb the PC on the silicon dioxide, which was then collected by centrifugation at $15^{\circ} \mathrm{C}$ for $20 \mathrm{~min}$ at $3500 \times \mathrm{g}$. This precipitate was washed at first with distilled water and suspended in $0.2 \mathrm{M}$ of acetate buffer at pH 5.5 containing PLD and NaGHB. The incubation was conducted at $35^{\circ} \mathrm{C}$ at $400 \mathrm{rpm}$ for $12 \mathrm{~h}$. This method was also compared with a liquid-liquid process where a solution containing PC in diethylether was mixed with a PLD solution containing NaGHB. This incubation was performed at $30{ }^{\circ} \mathrm{C}$ and $400 \mathrm{rpm}$. The aqueous-solid system appeared to be much better for various reasons: firstly, the conversion rate of PC was close to $100 \%$, and the purity was up to $97 \%$; secondly, it was an environmentally friendly method which was scaled up from 2 to $250 \mathrm{~mL}$ of reaction volume yielding $94 \%$ of PX-21 and just $2.3 \%$ of PA; and at the end, the free PLD solution was reused for different cycles, allowing a yield of $70.7 \%$ of $\mathrm{PB}$ after the 5 th cycle. 


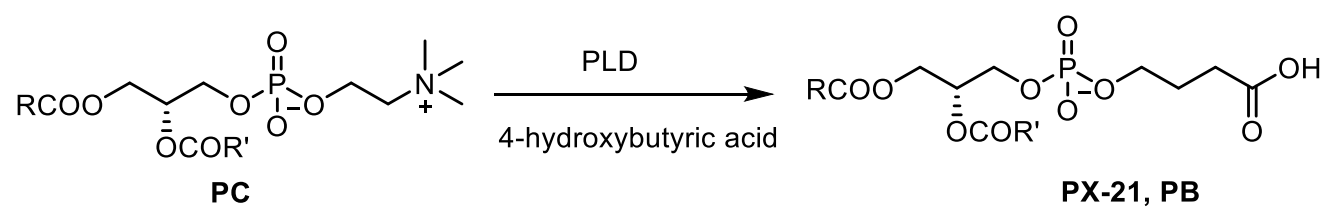

Scheme 12. Schematic equation of the synthesis of phosphatidylhydroxybutyrate (PB, PX-21).

\subsubsection{Phosphatidylpanthenol}

In the current year (2020), Yamamoto et al. exploited the PLD-catalyzed transphosphatidylation of PC to prepare a new PL, the phosphatidylpanthenol (PX-22, see Scheme 13). In fact, D-panthenol is known to be a pro-vitamin B5 and to possess many interesting properties such as being wound-healing, anti-oxidative and anti-inflammatory. However, its high hydrophilicity requires the use of emulsifiers. The idea of the authors was to link the D-panthenol as the polar head of a new PL, in order to enhance its biocompatibility and to test its anti-inflammatory activity on the macrophagelike RAW264.7 cell. The results were very interesting showing that the PX-22 was better than the D-panthenol from an anti-inflammatory point of view. The synthesis was performed as follows: $31 \mathrm{mM}$ soyPC in ethyl acetate was incubated with PLD from Streptomyces sp. in sodium acetate buffer $0.2 \mathrm{M}$ at pH 5.6, $10 \mathrm{mM}$ $\mathrm{CaCl}_{2}$ and D-panthenol with a concentration of $0.625 \mathrm{M}$. The incubation was performed at $37^{\circ} \mathrm{C}$ for $24 \mathrm{~h}$ and provided, after precipitation and extraction, the desired product PX-22 with a $96 \%$ yield.

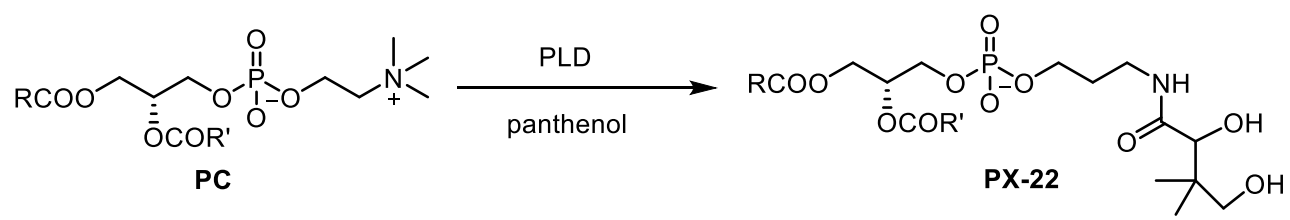

Scheme 13. Schematic equation of the synthesis of phosphatidylpanthenol (PX-22).

\section{Conclusions}

The inclusion of a bioactive nucleophile in the PL backbone as the polar head part of the molecule is a very suitable strategy in order to stabilize and to allow a better release of active alcohols in vivo because the PL residue represents a nontoxic carrier moiety with a high affinity for cell membranes and a great hydrophobicity which prevents bioactive moieties degradation. For those reasons, the polar head modified PLs (PX-1 to PX-21) reported in this review present distinctive properties, which are actually exploited in very diverse fields of applications and can be considered as prodrugs. In this mainframe, the development of practical methods for the preparation of the structurally variable polar head-modified PLs is an important prerequisite to achieve the establishment of structure-activity relationships of these compounds. A biocatalytic approach for the synthesis of modified PLs is preferred when compared to the chemical processes especially due to the very high selectivity and the use of safer reagents and milder conditions. The modification of the polar head of PC (the most abundant natural PL) is performed by using the PLD from bacterial sources. This enzyme catalyzes the hydrolysis of PC to choline and PA, but in the presence of an appropriate acceptor (an alcohol), it performs the transphosphatidylation reaction, which allows the modification of the polar head. Parameters which may affect the ratios between the production of the new PLs and PA and the overall production yield depends on the reaction conditions, in particular, the concentration and nature of the alcohol, as well as the enzymatic source. Very different strains of PLD have been studied, some of which was shown to be highly able to perform transphosphatidylation reactions. The availability of enzymes which possess a very high substrate specificity and high transfer capacity offers a very appealing approach which allows the synthesis of natural and synthetic polar head modified PLs to be performed, without any comparison with chemical approaches. All the bioconversions described in this review follow a relatively simple and well-established procedure already known for the general scheme in the middle of the 1990s, which allows the recovery of numerous new products and the 
investigations on their potential effects both in the medical field as new drug delivery systems, as well as for the cosmetic industry, thanks to their antibacterial and antioxidative activities. This overview will hopefully constitute a source of inspiration for new potential investigations on PLs' fertile area of research.

Author Contributions: Conceptualization, P.D., writing—original draft preparation, C.A., P.D.; writing—review and editing, C.A., F.D., L.R., P.D.; funding acquisition, P.D. All authors have read and agreed to the published version of the manuscript.

Funding: This research was funded by Fondazione Cariplo-INNOVHUB-SSI, grant n. 2017-1015, Project SOAVE (Seed and vegetable Oils Active Valorization through Enzymes; Bando congiunto Ricerca Integrata sulle Biotecnologie industriali e sulla Bioeconomia ed. 2017).

Conflicts of Interest: The authors declare no conflict of interest.

\section{References}

1. Nickels, J.D.; Smith, J.C.; Cheng, X. Lateral organization, bilayer asymmetry, and inter-leaflet coupling of biological membranes. Chem. Phys. Lipids 2015, 192, 87-99. [CrossRef] [PubMed]

2. Dowhan, W.; Bogdanov, M.; Mileykovskaya, E. CHAPTER 1-Functional roles of lipids in membranes. In Biochemistry of Lipids, Lipoproteins and Membranes, 5th ed.; Vance, D.E., Vance, J.E., Eds.; Elsevier: San Diego, CA, USA, 2008; pp. 1-37. [CrossRef]

3. Vance, D.E.; Vance, J.E. CHAPTER 8-Phospholipid biosynthesis in eukaryotes. In Biochemistry of Lipids, Lipoproteins and Membranes, 5th ed.; Vance, D.E., Vance, J.E., Eds.; Elsevier: San Diego, CA, USA, 2008; pp. 213-244. [CrossRef]

4. Isabel, E.-S.; Arantxa, R.-C.; Susana, M.; Agustin, R.-G.; Jose, M.O.; de Ana Ramirez, M. Beneficial Effects of Bioactive Phospholipids: Genomic Bases. Curr. Nutr. Food Sci. 2011, 7, 145-154. [CrossRef]

5. Falconi, M.; Ciccone, S.; D'Arrigo, P.; Viani, F.; Sorge, R.; Novelli, G.; Patrizi, P.; Desideri, A.; Biocca, S. Design of a novel LOX-1 receptor antagonist mimicking the natural substrate. Biochem. Biophys. Res. Commun. 2013, 438, 340-345. [CrossRef]

6. Niezgoda, N.; Gliszczyñska, A.; Gladkowski, W.; Kempiñska, K.; Wietrzyk, J.; Wawrzeñczyk, C. Phosphatidylcholine with cis-9, trans-11 and trans-10, cis-12 Conjugated Linoleic Acid Isomers: Synthesis and Cytotoxic Studies. Aust. J. Chem. 2015, 68, 1065-1075. [CrossRef]

7. D'Arrigo, P.; Scotti, M. Lysophospholipids: Synthesis and Biological Aspects. Curr. Org. Chem. 2013, 17, 812-830. [CrossRef]

8. Küllenberg, D.; Taylor, L.A.; Schneider, M.; Massing, U. Health effects of dietary phospholipids. Lipids Health Dis. 2012, 11, 3. [CrossRef]

9. Schverer, M.; O'Mahony, S.M.; O'Riordan, K.J.; Donoso, F.; Roy, B.L.; Stanton, C.; Dinan, T.G.; Schellekens, H.; Cryan, J.F. Dietary phospholipids: Role in cognitive processes across the lifespan. Neurosci. Biobehav. Rev. 2020, 111, 183-193. [CrossRef]

10. Baldassarre, F.; Allegretti, C.; Tessaro, D.; Carata, E.; Citti, C.; Vergaro, V.; Nobile, C.; Cannazza, G.; D'Arrigo, P.; Mele, A.; et al. Biocatalytic Synthesis of Phospholipids and Their Application as Coating Agents for CaCO3 Nano-crystals: Characterization and Intracellular Localization Analysis. ChemistrySelect 2016, 1 , 6507-6514. [CrossRef]

11. Ishii, F.; Nii, T. Chapter 22-Lipid emulsions and lipid vesicles prepared from various phospholipids as drug carriers. In Colloid and Interface Science in Pharmaceutical Research and Development; Ohshima, H., Makino, K., Eds.; Elsevier: San Diego, CA, USA, 2014; pp. 469-501. [CrossRef]

12. Khan, I.; Elhissi, A.; Shah, M.; Alhnan, M.A.; Ahmed, W. Liposome-based carrier systems and devices used for pulmonary drug delivery. In Biomaterials and Medical Tribology; Davim, J.P., Ed.; Woodhead Publishing: Cambridge, UK, 2013; pp. 395-443. [CrossRef]

13. Li, J.; Wang, X.; Zhang, T.; Wang, C.; Huang, Z.; Luo, X.; Deng, Y. A review on phospholipids and their main applications in drug delivery systems. Asian J. Pharm. Sci. 2015, 10, 81-98. [CrossRef]

14. Yadav, S.; Sharma, A.K.; Kumar, P. Nanoscale Self-Assembly for Therapeutic Delivery. Front. Bioeng. Biotechnol. 2020, 8. [CrossRef]

15. Allen, T.M.; Cullis, P.R. Liposomal drug delivery systems: From concept to clinical applications. Adv. Drug Deliv. Rev. 2013, 65, 36-48. [CrossRef] 
16. Sercombe, L.; Veerati, T.; Moheimani, F.; Wu, S.Y.; Sood, A.K.; Hua, S. Advances and Challenges of Liposome Assisted Drug Delivery. Front. Pharmacol. 2015, 6. [CrossRef]

17. Ozturk, B.; McClements, D.J. Progress in natural emulsifiers for utilization in food emulsions. Curr. Opin. Food Sci. 2016, 7, 1-6. [CrossRef]

18. Koprivnjak, O.; Škevin, D.; Valić, S.; Majetić, V.; Petričević, S.; Ljubenkov, I. The antioxidant capacity and oxidative stability of virgin olive oil enriched with phospholipids. Food Chem. 2008, 111, 121-126. [CrossRef]

19. Cui, L.; Decker, E.A. Phospholipids in foods: Prooxidants or antioxidants? J. Sci. Food Agric. 2016, 96, $18-31$. [CrossRef] [PubMed]

20. Zabielska-Koczywas, K.; Lechowski, R. The Use of Liposomes and Nanoparticles as Drug Delivery Systems to Improve Cancer Treatment in Dogs and Cats. Molecules 2017, 22, 2167. [CrossRef]

21. D'Arrigo, P.; Fasoli, E.; Pedrocchi-Fantoni, G.; Rossi, C.; Saraceno, C.; Tessaro, D.; Servi, S. A practical selective synthesis of mixed short/long chains glycerophosphocholines. Chem. Phys. Lipids 2007, 147, 113-118. [CrossRef]

22. Gładkowski, W.; Chojnacka, A.; Kiełbowicz, G.; Trziszka, T.; Wawrzeńczyk, C. Isolation of Pure Phospholipid Fraction from Egg Yolk. J. Am. Oil Chem. Soc. 2012, 89, 179-182. [CrossRef]

23. Weber, E.J. Compositions of commercial corn and soybean lecithins. J. Am. Oil Chem. Soc. 1981, 58, 898-901. [CrossRef]

24. Robert, C.; Couëdelo, L.; Vaysse, C.; Michalski, M.-C. Vegetable lecithins: A review of their compositional diversity, impact on lipid metabolism and potential in cardiometabolic disease prevention. Biochimie 2020, 169, 121-132. [CrossRef]

25. Klang, V.; Valenta, C. Lecithin-based nanoemulsions. J. Drug Deliv. Sci. Technol. 2011, 21, 55-76. [CrossRef]

26. Gliszczyńska, A.; Niezgoda, N.; Gładkowski, W.; Świtalska, M.; Wietrzyk, J. Isoprenoid-phospholipid conjugates as potential therapeutic agents: Synthesis, characterization and antiproliferative studies. PLoS ONE 2017, 12, e0172238. [CrossRef] [PubMed]

27. Eibl, H. Synthesis of glycerophospholipids. Chem. Phys. Lipids 1980, 26, 405-429. [CrossRef]

28. Ali, S.; Bittman, R. Facile diacylation of glycidyl tosylate. Chiral synthesis of symmetric-chain glycerophospholipids. J. Org. Chem. 1988, 53, 5547-5549. [CrossRef]

29. D'Arrigo, P.; Servi, S. Synthesis of Lysophospholipids. Molecules 2010, 15, 1354. [CrossRef]

30. Lindberg, J.; Ekeroth, J.; Konradsson, P. Efficient Synthesis of Phospholipids from Glycidyl Phosphates. J. Org. Chem. 2002, 67, 194-199. [CrossRef]

31. Fasoli, E.; Arnone, A.; Caligiuri, A.; D'Arrigo, P.; de Ferra, L.; Servi, S. Tin-mediated synthesis of lyso-phospholipids. Org. Biomol. Chem. 2006, 4, 2974-2978. [CrossRef]

32. Massing, U.; Eibl, H. New optically pure dimethylacetals of glyceraldehydes and their application for lipid and phospholipid synthesis. Chem. Phys. Lipids 1995, 76, 211-224. [CrossRef]

33. D'Arrigo, P.; De Ferra, L.; Piergianni, V.; Selva, A.; Servi, S.; Strini, A. Preparative transformation of natural phospholipids catalysed by phospholipase D from Streptomyces. J. Chem. Soc. Perkin Trans. 1 1996, 2651-2656. [CrossRef]

34. Adlercreutz, P.; Virto, C.; Persson, M.; Vaz, S.; Adlercreutz, D.; Svensson, I.; Wehtje, E. Enzymatic conversions of polar lipids. Principles, problems and solutions. J. Mol. Catal. B Enzym. 2001, 11, 173-178. [CrossRef]

35. Bornscheuer, U.T. Enzymes in Lipid Modification. Annu. Rev. Food Sci. Technol. 2018, 9, 85-103. [CrossRef] [PubMed]

36. Anthonsen, T.; D'Arrigo, P.; Pedrocchi-Fantoni, G.; Secundo, F.; Servi, S.; Sundby, E. Phospholipids hydrolysis in organic solvents catalysed by immobilised phospholipase C. J. Mol. Catal. B Enzym. 1999, 6, 125-132. [CrossRef]

37. Zhang, Z.; Chen, M.; Xu, W.; Zhang, W.; Zhang, T.; Guang, C.; Mu, W. Microbial phospholipase D: Identification, modification and application. Trends Food Sci. Technol. 2020, 96, 145-156. [CrossRef]

38. Kolesnikov, Y.S.; Nokhrina, K.P.; Kretynin, S.V.; Volotovski, I.D.; Martinec, J.; Romanov, G.A.; Kravets, V.S. Molecular structure of phospholipase D and regulatory mechanisms of its activity in plant and animal cells. Biochem. Mosc. 2012, 77, 1-14. [CrossRef]

39. Bargmann, B.O.R.; Munnik, T. The role of phospholipase D in plant stress responses. Curr. Opin. Plant Biol. 2006, 9, 515-522. [CrossRef] 
40. Subileau, M.; Jan, A.-H.; Dubreucq, E. Chapter 3-Lipases/Acyltransferases for Lipid Modification in Aqueous Media. In Lipid Modification by Enzymes and Engineered Microbes; Bornscheuer, U.T., Ed.; AOCS Press: Urbana, IL, USA, 2018; pp. 45-68. [CrossRef]

41. D'Arrigo, P.; Servi, S. Using phospholipases for phospholipid modification. Trends Biotechnol. 1997, 15, 90-96. [CrossRef]

42. Cerminati, S.; Paoletti, L.; Aguirre, A.; Peirú, S.; Menzella, H.G.; Castelli, M.E. Industrial uses of phospholipases: Current state and future applications. Appl. Microbiol. Biotechnol. 2019, 103, 2571-2582. [CrossRef]

43. Joensuu, M.; Wallis, T.P.; Saber, S.H.; Meunier, F.A. Phospholipases in neuronal function: A role in learning and memory? J. Neurochem. 2019, 153, e14918. [CrossRef]

44. Servi, S. Phospholipases as synthetic catalysts. Top. Curr. Chem. 1999, 200, 127-158.

45. D'Arrigo, P.; de Ferra, L.; Piergianni, V.; Ricci, A.; Scarcelli, D.; Servi, S. Phospholipase D from Streptomyces catalyses the transfer of secondary alcohols. J. Chem. Soc. Chem. Commun. 1994, 1709-1710. [CrossRef]

46. Allegretti, C.; Bono, A.; D’Arrigo, P.; Denuccio, F.; De Simeis, D.; Di Lecce, G.; Serra, S.; Tessaro, D.; Viola, M. Valorization of Corn Seed Oil Acid Degumming Waste for Phospholipids Preparation by Phospholipase D-Mediated Processes. Catalysts 2020, 10, 809. [CrossRef]

47. Carrea, G.; D’Arrigo, P.; Mazzotti, M.; Secundo, F.; Servi, S. On the kinetic mechanism of phospholipase D from Streptomyces SP. in an emulsion system. Biocatal. Biotransform. 1997, 15, 251-264. [CrossRef]

48. Bossi, L.; D'Arrigo, P.; Pedrocchi-Fantoni, G.; Mele, A.; Servi, S.; Leiros, I. The substrate requirements of phospholipase D. J. Mol. Catal. B Enzym. 2001, 11, 433-438. [CrossRef]

49. D’Arrigo, P.; Fasoli, E.; Pedrocchi-Fantoni, G.; Servi, S.; Tessaro, D. Membrane assisted coupled enzyme system for phospholipid modification. Enzym. Microb. Technol. 2005, 37, 435-440. [CrossRef]

50. Secundo, F.; Carrea, G.; D’Arrigo, P.; Servi, S. Evidence for an Essential Lysyl Residue in Phospholipase D from Streptomyces sp. by Modification with Diethyl Pyrocarbonate and Pyridoxal 5-Phosphate. Biochemistry 1996, 35, 9631-9636. [CrossRef]

51. Leiros, I.; Hough, E.; D’Arrigo, P.; Carrea, G.; Pedrocchi-Fantoni, G.; Secundo, F.; Servi, S. Crystallization and preliminary X-ray diffraction studies of phospholipase D from Streptomyces sp. Acta Crystallogr. Sect. D Biol. Crystallogr. 2000, 56, 466-468. [CrossRef]

52. Carrea, G.; D'Arrigo, P.; Secundo, F.; Servi, S. Purification and applications of a phospholipase D from a new strain of Streptomyces. Biotechnol. Lett. 1997, 19, 1083-1085. [CrossRef]

53. Carrea, G.; D'Arrigo, P.; Piergianni, V.; Roncaglio, S.; Secundo, F.; Servi, S. Purification and properties of two phospholipases D from Streptomyces sp. Biochim. Et Biophys. Acta Lipids Lipid Metab. 1995, 1255, $273-279$. [CrossRef]

54. Liu, X.; Shiihara, M.; Taniwaki, N.; Shirasaka, N.; Atsumi, Y.; Shiojiri, M. Phosphatidylserine: Biology, Technologies, and Applications. In Polar Lipids; Ahmad, M.U., Xu, X., Eds.; Elsevier: San Diego, CA, USA, 2015; pp. 145-184. [CrossRef]

55. Juneja, L.R.; Kazuoka, T.; Goto, N.; Yamane, T.; Shimizu, S. Conversion of phosphatidylcholine to phosphatidylserine by various phospholipases D in the presence of 1- or d-serine. Biochim. Biophys. Acta Lipids Lipid Metab. 1989, 1003, 277-283. [CrossRef]

56. D'Arrigo, P.; Cerioli, L.; Chiappe, C.; Panzeri, W.; Tessaro, D.; Mele, A. Improvements in the enzymatic synthesis of phosphatidylserine employing ionic liquids. J. Mol. Catal. B Enzym. 2012, 84, 132-135. [CrossRef]

57. Duan, Z.-Q.; Hu, F. Highly efficient synthesis of phosphatidylserine in the eco-friendly solvent $\gamma$-valerolactone. Green Chem. 2012, 14, 1581-1583. [CrossRef]

58. Duan, Z.-Q.; Hu, F. Efficient synthesis of phosphatidylserine in 2-methyltetrahydrofuran. J. Biotechnol. 2013, 163, 45-49. [CrossRef] [PubMed]

59. Chen, S.; Xu, L.; Li, Y.; Hao, N.; Yan, M. Bioconversion of Phosphatidylserine by Phospholipase D from Streptomyces racemochromogenes in a Microaqueous Water-Immiscible Organic Solvent. Biosci. Biotechnol. Biochem. 2013, 77, 1939-1941. [CrossRef] [PubMed]

60. Yang, S.-L.; Duan, Z.-Q. Insight into enzymatic synthesis of phosphatidylserine in deep eutectic solvents. Catal. Commun. 2016, 82, 16-19. [CrossRef]

61. Qin, W.; Wu, C.; Song, W.; Chen, X.; Liu, J.; Luo, Q.; Liu, L. A novel high-yield process of phospholipase D-mediated phosphatidylserine production with cyclopentyl methyl ether. Process Biochem. 2018, 66, 146-149. [CrossRef] 
62. Gregoriadis, G. Liposomes for drugs and vaccines. Trends Biotechnol. 1985, 3, 235-241. [CrossRef]

63. Sakdiset, P.; Okada, A.; Todo, H.; Sugibayashi, K. Selection of phospholipids to design liposome preparations with high skin penetration-enhancing effects. J. Drug Deliv. Sci. Technol. 2018, 44, 58-64. [CrossRef]

64. Hossann, M.; Wiggenhorn, M.; Schwerdt, A.; Wachholz, K.; Teichert, N.; Eibl, H.; Issels, R.D.; Lindner, L.H. In vitro stability and content release properties of phosphatidylglyceroglycerol containing thermosensitive liposomes. Biochim. Et Biophys. Acta Biomembr. 2007, 1768, 2491-2499. [CrossRef]

65. Mazela, J.; Merritt, T.A.; Gadzinowski, J.; Sinha, S. Evolution of pulmonary surfactants for the treatment of neonatal respiratory distress syndrome and paediatric lung diseases. Acta Paediatr. 2006, 95, 1036-1048. [CrossRef]

66. Juneja, L.R.; Hibi, N.; Inagaki, N.; Yamane, T.; Shimizu, S. Comparative study on conversion of phosphatidylcholine to phosphatidylglycerol by cabbage phospholipase D in micelle and emulsion systems. Enzym. Microb. Technol. 1987, 9, 350-354. [CrossRef]

67. Piazza, G.J.; Marmer, W.N. Conversion of Phosphatidylcholine to Phosphatidylglycerol with Phospholipase D and Glycerol. J. Am. Oil Chem. Soc. 2007, 84, 645-651. [CrossRef]

68. D'Arrigo, P.; de Ferra, L.; Pedrocchi-Fantoni, G.; Scarcelli, D.; Servi, S.; Strini, A. Enzyme-mediated synthesis of two diastereoisomeric forms of phosphatidylglycerol and of diphosphatidylglycerol (cardiolipin). J. Chem. Soc. Perkin Trans. 1 1996, 2657-2660. [CrossRef]

69. Schlame, M.; Rua, D.; Greenberg, M.L. The biosynthesis and functional role of cardiolipin. Prog. Lipid Res. 2000, 39, 257-288. [CrossRef]

70. Claypool, S.M.; Koehler, C.M. The complexity of cardiolipin in health and disease. Trends Biochem. Sci. 2012, 37, 32-41. [CrossRef]

71. Calzada, E.; Onguka, O.; Claypool, S.M. Chapter Two-Phosphatidylethanolamine Metabolism in Health and Disease. In International Review of Cell and Molecular Biology; Jeon, K.W., Ed.; Academic Press: Cambridge, MA, USA, 2016; Volume 321, pp. 29-88.

72. Patel, D.; Witt, S.N. Ethanolamine and Phosphatidylethanolamine: Partners in Health and Disease. Oxidative Med. Cell. Longev. 2017, 2017, 4829180. [CrossRef]

73. Sun, N.; Chen, J.; Bao, Z.; Wang, D.; An, B.; Lin, S. Egg Yolk Phosphatidylethanolamine: Extraction Optimization, Antioxidative Activity, and Molecular Structure Profiling. J. Food Sci. 2019, 84, 1002-1011. [CrossRef]

74. Juneja, L.R.; Toru, K.; Tsuneo, Y.; Shoichi, S. Kinetic evaluation of conversion of phosphatidylcholine to phosphatidylethanolamine by phospholipase D from different sources. Biochim. Biophys. Acta Lipids Lipid Metab. 1988, 960, 334-341. [CrossRef]

75. Dippe, M.; Mrestani-Klaus, C.; Schierhorn, A.; Ulbrich-Hofmann, R. Phospholipase D-catalyzed synthesis of new phospholipids with polar head groups. Chem. Phys. Lipids 2008, 152, 71-77. [CrossRef]

76. Nagao, A.; Ishida, N.; Terao, J. Synthesis of 6-phosphatidyl-L-ascorbic acid by phospholipase D. Lipids 1991, 26, 390-394. [CrossRef]

77. Koga, T.; Nagao, A.; Terao, J.; Sawada, K.; Mukai, K. Synthesis of a phosphatidyl derivative of vitamin E and its antioxidant activity in phospholipid bilayers. Lipids 1994, 29, 83. [CrossRef]

78. Takami, M.; Hidaka, N.; Miki, S.; Suzuki, Y. Enzymatic Synthesis of Novel Phosphatidylkojic Acid and Phosphatidylarbutin, and Their Inhibitory Effects on Tyrosinase Activity. Biosci. Biotechnol. Biochem. 1994, 58, 1716-1717. [CrossRef]

79. Takami, M.; Suzuki, Y. Enzymatic Synthesis of Novel Phosphatidylgenipin, and Its Enhanced Cytotoxity. Biosci. Biotechnol. Biochem. 1994, 58, 1897-1898. [CrossRef]

80. Yamamoto, Y.; Hosokawa, M.; Kurihara, H.; Miyashita, K. Preparation of Phosphatidylated Terpenes via Phospholipase D-Mediated Transphosphatidylation. J. Am. Oil Chem. Soc. 2008, 85, 313. [CrossRef]

81. Casado, V.; Reglero, G.; Torres, C.F. Production and Scale-up of phosphatidyl-tyrosol catalyzed by a food grade phospholipase D. Food Bioprod. Process. 2013, 91, 599-608. [CrossRef]

82. Di Benedetto, R.; Varì, R.; Scazzocchio, B.; Filesi, C.; Santangelo, C.; Giovannini, C.; Matarrese, P.; D'Archivio, M.; Masella, R. Tyrosol, the major extra virgin olive oil compound, restored intracellular antioxidant defences in spite of its weak antioxidative effectiveness. Nutr. Metab. Cardiovasc. Dis. 2007, 17, 535-545. [CrossRef] 
83. Song, S.; Cheong, L.-Z.; Falkeborg, M.; Liu, L.; Dong, M.; Jensen, H.M.; Bertelsen, K.; Thorsen, M.; Tan, T.; Xu, X.; et al. Facile Synthesis of Phosphatidyl Saccharides for Preparation of Anionic Nanoliposomes with Enhanced Stability. PLoS ONE 2013, 8, e73891. [CrossRef]

84. Torchilin, V.P. Recent advances with liposomes as pharmaceutical carriers. Nat. Rev. Drug Discov. 2005, 4, 145-160. [CrossRef]

85. Nagatsuka, Y.; Kasama, T.; Ohashi, Y.; Uzawa, J.; Ono, Y.; Shimizu, K.; Hirabayashi, Y. A new phosphoglycerolipid, 'phosphatidylglucose', found in human cord red cells by multi-reactive monoclonal anti-i cold agglutinin, mAb GL-1/GL-2. FEBS Lett. 2001, 497, 141-147. [CrossRef]

86. Inoue, A.; Adachi, M.; Damnjanović, J.; Nakano, H.; Iwasaki, Y. Direct Enzymatic Synthesis of 1-Phosphatidyl- $\beta$-D-glucose by Engineered Phospholipase D. ChemistrySelect 2016, 1, 4121-4125. [CrossRef]

87. Arranz-Martínez, P.; Casado, V.; Reglero, G.; Torres, C.F. Novel glyceryl ethers phospholipids produced by solid to solid transphosphatidylation in the presence of a food grade phospholipase D. Eur. J. Lipid Sci. Technol. 2017, 119, 1600427. [CrossRef]

88. Li, B.; Wang, J.; Li, H.; Zhang, X.; Duan, D.; Yu, W.; Zhao, B. Efficient and green aqueous-solid system for transphosphatidylation to produce phosphatidylhydroxybutyrate: Potential drugs for central nervous system's diseases. Biotechnol. Prog. 2019, 35, e2726. [CrossRef] [PubMed]

(C) 2020 by the authors. Licensee MDPI, Basel, Switzerland. This article is an open access article distributed under the terms and conditions of the Creative Commons Attribution (CC BY) license (http://creativecommons.org/licenses/by/4.0/). 